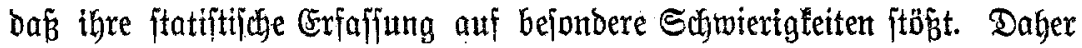
ift es ein Berotenft bes $\mathfrak{B}$ erfaffers ber vorltegenden Sdyrift, bie $\mathfrak{S o l} z=$

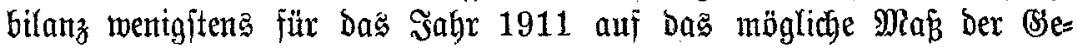
nautgleit feftgelegt zu haben. Für biefes Sahr ergibt fich in Starfen= burg und Rheinbeffen eine 5olzeinfubr bon 1032700 , eine $\mathfrak{X}$ usfubr von 773600 und fomit eine Mebreinfuhr von $259100 \mathrm{fm}$ - alleg in

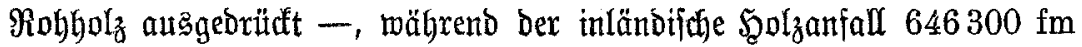
betrug. F̧ür Dberheffen ergeben ftch folgende Bahlen: Einfuhr 155400 ,

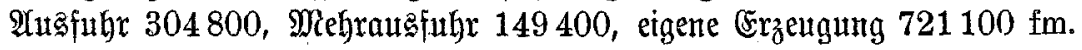
Fïr Den aamzen Staat Seefjen ijt aljo bie Scolzbilanz mit $109700 \mathrm{fm}$ Mehr $=$

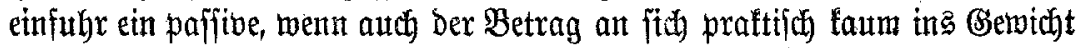
fällt und vielleicht in anderen Sabren auf bie pofitive Seite umichlagen fann.

Die Schrifit enthält aud wertoolfes gef duthtliches Matertal über ben

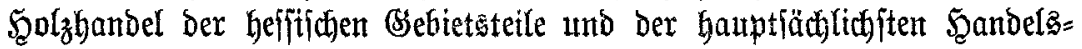
pläbe und ift, wie jufon geiagt, eine verotenftuolle, fletîige uno inter= efjante $\mathfrak{A r b e i t}$.

(5.

\title{
Nr. 62.
}

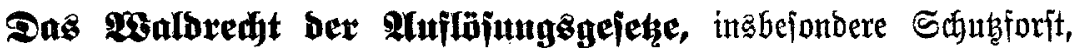
Waldgut und Waloftiftung, unter Aborud der gejeşlichen Bejttmmungen

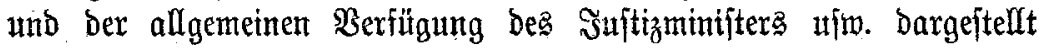

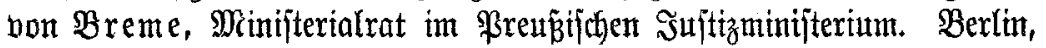
Berlag bon Beorg Stilfe, 1922.

$\mathfrak{u m}$ bie materiellen Sorteile ber ftbeifommififarifol gebunbenen $\mathfrak{W a l d}=$ befibung nach âflöjung ber Fibeifommifje bem $\mathfrak{B a l b e}$ żu erhalten, wurben in \$reutien etappenweije verichiedene Beroronungen und Siejebe

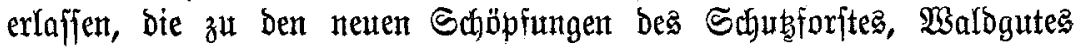

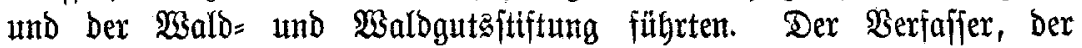
offenbar bei- ber Taufe tetnen Bornamen erbalten hat, hat als ftell= vertretender Präfident bes \&andes̄amtes für Familiengüter bejonderent

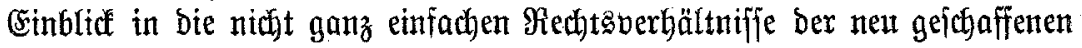
Rechtsgebilde und hat biejelben als berufenter șterpret in bem bor= liegenden şuch flax und ïberfithtlich bargeftellt.

Drudfehlerberiđtigung.

ऽ. 383 马etre 14 bon oben ftatt "ribtigerer" lies "widitigerer".

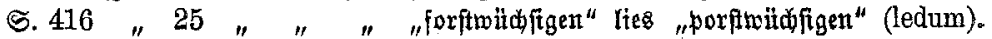

S. $423 " 8$ " unten lies "gegenüber ben $\mathrm{E}=$ (5rab".

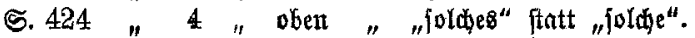

